\title{
The use of radionuclides in the study of calcium metabolism in man
}

\author{
By P. Tothill, Department of Medical Physics, The Royal Infirmary, Edinburgh \\ $\mathrm{EH}_{3}, \mathrm{YW}$
}

The applications of radionuclides to studies of calcium metabolism in man can be considered in four main groups: (I) absorption and endogenous faecal loss measurements, (2) assessment of bone formation rate, (3) bone visualization, (4) determination of total or partial body $\mathrm{Ca}$ by neutron activation analysis.

There is no doubt that the best tracer for $\mathrm{Ca}$ is an isotope of $\mathrm{Ca}$, but as the physical properties of those available are limited, nuclides of other elements are often used (Table I). Only $\gamma$-ray emitters permit external counting, so that the use of ${ }^{45} \mathrm{Ca}$ is limited to sample-counting techniques. For radioactive materials administered to

Table I. Bone-seeking nuclides for tracer use

\begin{tabular}{|c|c|c|c|c|c|c|c|c|}
\hline & ${ }^{46} \mathrm{Ca}$ & ${ }^{40} \mathrm{Ca}$ & ${ }^{47} \mathrm{Ca}$ & ${ }^{88} \mathrm{Ca}$ & ${ }^{49} \mathrm{Ca}$ & ${ }^{85} \mathrm{Sr}$ & ${ }^{87} \mathrm{Sr}^{\mathrm{m}}$ & ${ }^{18} \mathrm{~F}$ \\
\hline Half-life & I $65 \mathrm{~d}$ & Stable & $4.7 \mathrm{~d}$ & Stable & $\begin{array}{l}8.9 \\
\min \end{array}$ & $65 \mathrm{~d}$ & $2 \cdot 8 \mathrm{~h}$ & $\mathrm{I} .8 \mathrm{~h}$ \\
\hline $\begin{array}{l}\text { Main } \gamma \text {-ray energy } \\
(\mathrm{MeV})\end{array}$ & - & - & $r \cdot 3^{x}$ & - & $3 \cdot$ ro & $0.5 \mathrm{I}$ & 0.39 & 0.51 \\
\hline $\begin{array}{l}\text { Maximum } \beta \text {-ray energy } \\
(\mathrm{MeV})\end{array}$ & 0.25 & - & $x \cdot 94$ & - & r.95 & - & - & 0.64 \\
\hline Natural abundance $(\%)$ & - & 0.0032 & 一 & 0.185 & - & - & - & 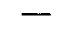 \\
\hline
\end{tabular}

humans, attention has to be paid to the radiation dose received by the subject. For this reason the amounts of ${ }^{45} \mathrm{Ca}$ and ${ }^{85} \mathrm{Sr}$, in particular, that can be administered are limited. By contrast, $\mathrm{mCi}$ amounts of generator-produced ${ }^{87} \mathrm{Sr}^{\mathrm{m}}$ ( $m$ denotes a metastable state) can be used, because of the short half-life. ${ }^{46} \mathrm{Ca}$ and ${ }^{48} \mathrm{Ca}$ are non-radioactive, but can be used as tracers, as they occur naturally in very small proportions, and can be administered in a highly enriched form. The increase in concentration of the isotope in samples of plasma or urine can then be assayed by mass spectrometry or neutron activation analysis (MacPherson, 1964). Stable $\mathrm{Sr}$ has also been used as a tracer for $\mathrm{Ca}$, but the quantities that are necessary may well disturb the metabolism under study.

Samples containing the $\gamma$-ray-emitting radionuclides are normally assayed by sodium iodide scintillation counting. ${ }^{47} \mathrm{Ca}$ has a radioactive 'daughter', ${ }^{77} \mathrm{Sc}$, but discrimination is easy. ${ }^{45} \mathrm{Ca}$ emits rather low-energy $\beta$-rays and is normally assayed by liquid scintillation counting. ${ }^{47} \mathrm{Ca}$ is always contaminated with ${ }^{45} \mathrm{Ca}$, 
in a proportion which is initially about $2 \%$, but which increases with time owing to the differences in decay rate. The presence of this contamination, coupled with the complex growth and decay of the ${ }^{47} \mathrm{Sc}$, and problems of blending and quenching in liquid scintillation counting make double isotope studies using ${ }^{45} \mathrm{Ca}$ and ${ }^{47} \mathrm{Ca}$ an intriguing exercise.

\section{Absorption studies}

As $\mathrm{Ca}$ is secreted in digestive juices, the classical balance study yields values only of net absorption. A correction can be made for the endogenous faecal loss of Ca (that part of the digestive juice $\mathrm{Ca}$ which is not reabsorbed) by injecting radioactive $\mathrm{Ca}$ intravenously, measuring the excreted radioactivity, and relating that in the stools to the urine or plasma specific activity.

True $\mathrm{Ca}$ absorption of a single tracer dose can be determined following oral administration of radioactive $\mathrm{Ca}$. The amount of carrier $\mathrm{Ca}$ administered with the radioisotope has a pronounced effect on the proportion absorbed, and standardization throughout any series is necessary.

The earliest measurements of radioactive $\mathrm{Ca}$ retention were based on faecal collections. However, these are subject to error due to the endogenous excretion of part of the absorbed material. The error depends on the time interval used. A long period of collection increases the error, but too short a period leads to a risk of incomplete recovery of unabsorbed $\mathrm{Ca}$. A measure of the possible error can be obtained from studies using injected radioactive $\mathrm{Ca}$. We found an average endogenous faecal loss of $8 \%$ in a $6 \mathrm{~d}$ stool collection, with a maximum of $20 \%$. For most purposes this error is negligible. More serious are likely to be errors arising from incomplete collections. These can be monitored by using a non-absorbable marker, and Ogg, Pearson \& Veall (I968), have made use of the ${ }^{47} \mathrm{Sc}$ which results from the decay of ${ }^{47} \mathrm{Ca}$.

Errors of collection can be eliminated by using a whole-body counter to measure total radioactivity in the patient immediately after oral administration of ${ }^{47} \mathrm{Ca}$ and then again after unabsorbed tracer has all been excreted. However, in this instance urinary loss of absorbed radioactive $\mathrm{Ca}$ is added to the endogenous faecal loss as an error, unless urine is collected and assayed. Our measurements show the magnitude of this combined error to average $18 \%$ for a $6 \mathrm{~d}$ period, rising to as much as $70 \%$, although amounts over $40 \%$ are uncommon.

Plasma concentrations of orally administered radioactive Ca were first used as an indicator of absorption by Bhandarkar, Bluhm, MacGregor \& Nordin (196r). After making measurements at various times they concluded that the concentration at $2 \mathrm{~h}$ provided the best indicator of absorption. Since that time many others have extended such investigations.

Double isotope tests permit the determination of true absorption without interference from endogenous faecal loss; in addition, if stools are collected, the latter can be estimated at the same time (De Grazia \& Rich, r964; Tothill \& Dellipiani, 1964). The intravenously administered isotope represents $100 \%$ 'absorption', and the ratio of the orally-administered isotope to the intravenously administered 
isotope in samples of urine or plasma taken with a suitable delay at periods of a day or more after administration provides the necessary information.

If plasma concentration curves of both isotopes are determined for a few hours after administration it is possible to carry out mathematical deconvolution procedures which establish the pattern of absorption and its total integral value ('Tothill \& Dellipiani, 1970; Tothill, Dellipiani \& Calvert, 1970). It is found that absorption starts very soon after administration and that the integral curve approximates to an inverse exponential function. From these analyses, total absorption can be obtained from measurements lasting for only a few hours, and calculations can be made of the fractional absorption rate at any given time. However, the technical difficulties of measuring ${ }^{45} \mathrm{Ca}$ and ${ }^{47} \mathrm{Ca}$ together make the method inconvenient for routine use.

The concentration curve of plasma radioactivity after a single oral dose has been subjected to kinetic analysis to derive a fractional absorption rate (Marshall \& Nordin, 1969). In the absence of direct evidence concerning the disappearance rate of injected radioactive $\mathrm{Ca}$, the fit to the curve is not unique. There is no doubt that there is a good correlation between the rate derived and $\mathrm{Ca}$ absorption, but the method cannot yield accurate information concerning the disappearance of activity from plasma.

Variations of the double isotope method are possible. A simplification is to use ${ }^{47} \mathrm{Ca}$ for both oral and intravenous administration, separating the two by a few days. Lutwak \& Shapiro (1964) had earlier used a large sample scintillation counter to measure forearm activity following oral administration of ${ }^{47} \mathrm{Ca}$ to obtain an index of absorption, and Macleod (1971) has applied this technique to a double administration test.

Double isotope tests present the opportunity of comparing the measured absorption with plasma concentrations of the oral isotope at various times. Tothill $e t$ al. (1970) found that the best correlation was obtained with a $2 \mathrm{~h}$ sample, vindicating the original choice by Bhandarkar et al. (1961). At earlier times variable delay in the start of absorption reduces the agreement, while at later times differences in the rate of clearance have an increased influence.

$\mathrm{Sr}$ isotopes are of little use in absorption studies, as $\mathrm{Sr}$ is absorbed less readily and excreted more actively than $\mathrm{Ca}$.

\section{Bone turnover studies}

The tracer content of bone can be considered in two portions, an exchangeable fraction in which concentration follows that in body fluids, and a fraction due to accretion, in which $\mathrm{Ca}$ is deposited irreversibly. Most kinetic studies are concerned with the determination of bone formation rate (accretion). The principles and basic formula were first published by Bauer, Carlsson \& Lindquist (1955). The early work assumed a single, homogeneous miscible Ca pool. This is certainly an oversimplification and leads to errors, and a dependence of the calculated accretion rate on the part of the specific activity curve used. Later developments have introduced $33(1) 3$ 
up to four compartments, mostly on the basis of the number of exponential terms needed to represent the plasma specific activity curve. Heaney ( 1963 ) prepared a valuable review of the problems attending the evaluation of $\mathrm{Ca}$ kinetic data which includes a discussion of the miscible pool. Heaney also considered the problem of the slowly exchangeable component in bone and the effect of resorption. He concludes that, although slow exchange is included in the measurement of apparent mineral deposition, true bone formation probably predominates. There is some evidence that bone resorption may release tracer into the pool within the period used for some kinetic investigations; if so, the methods would be invalid.

Most analyses have made use of exponential functions to characterize plasma specific activity or whole-body retention of tracers. This is a characteristic of compartmental analysis. Anderson, Emery, McAlister \& Osborn (1956) first observed that the plasma specific activity of ${ }^{45} \mathrm{Ca}$ could be represented by a power function for about $\mathrm{I} d$ after injection, that is, concentration, $\mathrm{C}=\mathrm{At}^{-a}$, where $\mathrm{A}$ and $\alpha$ are constants. A comparable fit using exponential terms would probably require six constants. The same group later attributed the observed behaviour to the atoms of radioactive $\mathrm{Ca}$ moving between different environments in the body according to random walk statistics (Anderson, Tomlinson, Osborn \& Wise, 1967; Wise, Osborn, Anderson \& Tomlinson, 1968).

The fit of a curve to the observed points can be extended over a longer period if an additional, exponential term is included, $\mathrm{C}=\mathrm{At}^{-a} \mathrm{e}^{-\beta \mathrm{t}}$ (a gamma function). $\beta$ is an additional constant. Burkinshaw, Marshall, Oxby, Spiers, Nordin \& Young (I969) have postulated that the first part of the curve, when the power function predominates, represents movement of tracer into a continuously expanding, exchangeable Ca pool, and that the emergence of an exponential function represents loss of radioactive $\mathrm{Ca}$ by excretion and by bone formation. A rather bold extrapolation of the straight line on a $\log -\log$ plot to day 7 permits calculation of the amount of radioactivity in the exchangeable pool at that time. When this is subtracted from the total body activity, the bone mineralization rate can be determined. The values determined are somewhat lower than those derived from the four-compartment models of Bauer \& Ray (1958) and Aubert \& Milhaud (r960), and considerably lower than those calculated from the original single-exchangeable-pool hypothesis.

Combinations of power functions and exponential functions have also been used to characterize the whole-body retention of all the alkaline earths. The most comprehensive function to date has been proposed by a committee of the International Commission for Radiological Protection chaired by Marshall (International Commission for Radiological Protection, 1973). They propose a six-parameter model of bodily retention which is found to fit most available data for $\mathrm{Ca}, \mathrm{Sr}$, barium and radium to within $20 \%$, over a period from $15 \mathrm{~min}$ to 100 years. Although a factor for bone formation rate is incorporated into the equation, it has not been suggested that the function can be used to derive a measure of accretion rate in an individual case. The main purpose of the model is to permit calculations of absorbed radiation dose.

It is widely accepted that once $\mathrm{Sr}$ has become attached to bone it is a faithful 
tracer for Ca. Although this assumption is not completely valid, ${ }^{85} \mathrm{Sr}$ is for most purposes a valuable material for long-term studies.

\section{Bone visualization}

There has been a rapid development of bone scanning in recent years, primarily with the aim of tumour detection. Short-lived, bone-seeking radionuclides are injected, and sites of increased uptake determined by examination with a scanner or gamma camera.

Bone scintigraphy may seem to have little relevance to nutrition studies. However, quantitative scanning of other organs has proved valuable in investigating their function, particularly when serial studies are performed to provide dynamic infor-

mation. It may be that such methods can be applied to bone studies, but because of its dispersed shape the skeleton does not lend itself to quantitative uptake measurements nearly so well as to organs such as the kidney or liver.

\section{Total body $\mathrm{Ca}$ determination}

Until the advent of in vivo neutron activation analysis there was no way of assessing the total $\mathrm{Ca}$ content of an intact human or other animal. The feasibility of determining amounts of elements in the body by this technique was first demonstrated by Anderson, Osborn, Tomlinson, Newton, Rundo, Salmon \& Smith (1964). They exposed two volunteers to a wide beam of $\mathrm{I}_{4} \mathrm{MeV}$ neutrons and then measured the induced radioactivity in a sensitive whole-body counter. Determinations of sodium and chlorine were made, and an indication was obtained that Ca assay should be possible. The first group to apply neutron activation analysis to the determination of whole-body $\mathrm{Ca}$ in patients was Chamberlain, Fremlin, Peters \& Philip (1968) at Birmingham. They used rather lower-energy neutrons from a cyclotron, and made no attempt at absolute calibration, contending that changes in a patient's Ca content during the course of a disease or its treatment were more important. These and other early developments used neutron sources that were originally intended for physics research and not conveniently situated for clinical investigations. Difficulties were introduced by the 9 min half-life of the induced ${ }^{49} \mathrm{Ca}$, which calls for close proximity of the source and detector. Now that the value of the technique has become established, specially designed facilities are becoming available, such as that of Cohn, Shukla, Dombrowski \& Fairchild (1972) at the Brookhaven National Laboratory, New York, and Boddy, Holloway \& Elliott (1973) at East Kilbride. Accuracies of determination of total body $\mathrm{Ca}$ of a few percentage units are attainable with radiation doses of less than $x$ rem.

For some purposes the determination of $\mathrm{Ca}$ in part of the body is adequate, and for this a more modest neutron source suffices. Catto, McIntosh \& MacLeod (r973) at Aberdeen have described the use of a small plutonium-beryllium source to activate a hand. Such a technique is most likely to be useful in serial studies.

Periodic measurements of total body Ca have been used in the study of metabolic bone disease (Chamberlain, 1969). It is conceivable that the technique may find a 
place as a supplement to $\mathrm{Ca}$ balance and radionuclide turnover studies in a wider field.

\section{REFERENCES}

Anderson, J., Emery, E. W., McAlister, J. M. \& Osborn, S. B. (1956). Clin, Sci. 15, 567.

Anderson, J., Osborn, S. B., Tomlinson, R. W. S., Newton, D., Rundo, J., Salmon, L. \& Smith, J. W. (1964). Lancet ii, r201.

Anderson, J., Tomlinson, R. W. S., Osborn, S. B. \& Wise, M. E. (1967). Lancet i, 930.

Aubert, J.-P. \& Milhaud, G. (1960). Biochim. biophys. Acta 39, 122.

Bauer, G. C. H., Carlsson, A. \& Lindquist, B. (1955). Acta physiol. scand. 35, 56.

Bauer, G. C. H. \& Ray, R. D. (1958). F. Bone ft Surg. 40A, 17 r.

Bhandarkar, S. D., Bluhm, M. M., MacGregor, J. \& Nordin, B. E. C. (196r). Br. med. J. 2, 1539.

Boddy, K., Holloway, I. \& Elliott, A. (I973). Int. F. appl. Radiat. Isotopes 24, 428.

Burkinshaw, L., Marshall, D. H., Oxby, C. B., Spiers, F. W., Nordin, B. E. C. \& Young, M. M. (1969). Nature, Land. 222, 146.

Catto, G. R. D., McIntosh, J. A. R. \& MacLeod, M. (1973). Physics Med. Biol. r8, 508.

Chamberlain, M. J. (1969). New Scient. 18, 575.

Chamberlain, M. J., Fremlin, J. H., Peters, D. K. \& Philip, H. (1968). Br. med. F. 2, $5^{81}$.

Cohn, S. H., Shukla, K. K., Dombrowski, C. S. \& Fairchild, R. G. (1972). F. nucl. Med. 13, 487.

De Grazia, J. A. \& Rich, C. (1964). Metabolism I3, 650.

Heaney, R. P. (1963). Clin. Orthop. 31, I53.

International Commission for Radiological Protection (1973). Hlth Phys. 24, r25.

Lutwak, L. \& Shapiro, J. R. (1964). Science, N.Y. I44, I 55.

Macleod, M. A. (1971). fl R. nav. med. Serv. 57, 88 .

MacPherson, D. (1964). Medical Uses of ${ }^{47} \mathrm{Ca}$ p. I7. Vienna: International Atomic Energy Agency.

Marshall, D. H. \& Nordin, B. E. C. (1969). Nature, Lond. 222, 797.

Ogg, C. S., Pearson, J. V. \& Veall, N. (r968). Clin. Sci. 34, 327.

Tothill, P. \& Dellipiani, A. W. (1964). In Radioaktive Isotope in Klinik und Forschung Vol. 6, p. 86 [K. Fellinger and R. Höfer, editors]. Munich: Urban and Schwarzenburg.

Tothill, P. \& Dellipiani, A. W. (1970). In Radioaktive Isotope in Klinik und Forschung Vol. 9, p. 438 [K. Fellinger and R. Höfer, editors]. Munich: Urban and Schwarzenburg.

Tothill, P., Dellipiani, A. W. \& Calvert, J. (r970). Clin. Sci. 38, 27.

Wise, M. E., Osborn, S. B., Anderson, J. \& Tomlinson, R. W. S. (1968). Math. Biosci. 2 , 199. 